\title{
Downregulation of Nrf2 promotes radiation-induced apoptosis through Nrf2 mediated Notch signaling in non-small cell lung cancer cells
}

\author{
QIUYUE ZHAO ${ }^{1-4}$, AIHONG MAO ${ }^{1-4}$, JIAWEI YAN $^{1-4}$, CHAO SUN $^{1-3}$, CUIXIA DI $^{1-3}$, \\ XIN ZHOU ${ }^{1-3}$, HONGYAN LI ${ }^{1-3}$, RUOSHUI GUO ${ }^{5}$ and HONG ZHANG ${ }^{1-3}$ \\ ${ }^{1}$ Institute of Modern Physics, Chinese Academy of Sciences; ${ }^{2}$ Key Laboratory of Heavy Ion Radiation Medicine \\ of Chinese Academy of Sciences; ${ }^{3}$ Key Laboratory of Heavy Ion Radiation Medicine of Gansu Province, \\ Lanzhou, Gansu 730000; ${ }^{4}$ University of Chinese Academy of Sciences, Beijing 100039; \\ ${ }^{5}$ South China Agricultural University, Guangzhou, Guangdong 510642, P.R. China
}

Received September 16, 2015; Accepted December 3, 2015

DOI: 10.3892/ijo.2015.3301

\begin{abstract}
The nuclear factor erythroid-2-related factor 2 (Nrf2) is a crucial regulator of the cellular antioxidant system. Nrf2 is often constitutively activated in non-small cell lung cancer (NSCLC) cell lines, which promotes cytoprotection against oxidative stress and xenobiotics. Notch1 signaling is critically implicated in cell fate determination. It has been reported that Nf2 strongly regulates Notch1 activity. However, the role of Nrf2 mediated Notch1 signaling in response to ionizing radiation (IR) remains elusive. We report that knockdown of Nrf2 promotes radiation-induced apoptosis through Nrf2 mediated Notch1 signaling in NSCLC cells. IR activated Nrf2 in a dose-dependent manner and the expression of $\mathrm{Nrf} 2$ was significantly elevated at $4 \mathrm{~h}$ after exposure. RNAi-mediated reduction of Nrf2 significantly increased endogenous ROS levels, and decreased the expression of glutamate cysteine ligase catalytic subunit (GCLC), heme oxygenase-1 (HO-1) and NAD (P) H quinine oxidoreductase-1 (NQO1) in irradiated cells. Furthermore, decrease in Nrf2 expression significantly dampened Notch1 expression following ionizing radiation exposure, and potentiated IR-induced cellular apoptosis. These results demonstrated that Nrf2 could be activated by ionizing radiation, knockdown of Nrf 2 could promote radiation induced apoptosis and Nrf2-mediated Notch signaling is an important determinant in radioresistance of lung cancer cells.
\end{abstract}

\section{Introduction}

Lung cancer, the leading cause of cancer related deaths, is divided into small cell lung carcinoma (SCLC) and non-small cell lung carcinoma (NSCLC). NSCLC accounts for $85 \%$

Correspondence to: Dr Hong Zhang, Department of Heavy Ion Radiation Medicine, Institute of Modern Physics, Chinese Academy of Sciences, Lanzhou, Gansu 730000, P.R. China

E-mail: zhangh@impcas.ac.cn

Key words: nuclear factor erythroid-2-related factor 2, ionizing radiation, ROS, Notch1, lung cancer of all lung cancer cases, moreover, $\sim 70 \%$ of cases are at an advanced stage with unresectable tumors (1-3). Radiotherapy is routinely used for treatment of lung cancer. Ionizing radiation (IR) damage, which is caused indirectly by radiolysis of intracellular water, leads to formation of ROS. It has been confirmed that ROS plays a main role in the cytotoxic action after IR. Excessive ROS results in oxidative stress that attacks biological macromolecules and leads to cell deaths (4). Cancer cells possess antioxidant systems results in low endogenous ROS levels and protect cells from the cytotoxic effects of radiation. The capacity of cancer cells is superior to those of normal cells, which leads to the radio-resistance of cancer cells and radiotherapy failure (5).

Nrf2 is a crucial transcription factor regulating the expression of numerous antioxidant genes (6-9). Under basal conditions, Nrf2 is located in the cytoplasm, where it is sequestered by its inhibitor Kelch-like ECH-associated protein 1 (Keap1) (10-12). Under oxidative stress, however, oxidative modification of Keap1 allows Nrf2 to release from Keap1, and then Nrf2 translocates into the nucleus. Once in the nucleus, Nrf2 binds the antioxidant response element (ARE) and drives the expression of several downstream genes such as $\gamma$-glutamyl cysteine synthetase modifier subunit (GCLm), GCLC, HO-1 and NQO1 (13-16). Both loss of function mutations in Keap1 and gain of function mutation in Nrf2 lead to Nrf2 overexpression. Accumulated clues show that Nrf2 is overexpressed in various types of cancer cells, including lung cancer, esophageal squamous cancer and skin cancer. Constitutive Nrf2 activation has been implicated in the resistance of cancer cells to radiation therapy (10). Nrf2 has been reported to cross-talk with other pathways. Specifically, Nrf2 strongly regulated Notch1 activity. The Notch signaling is involved in proliferation, differentiation and cell decisions (17-20). Numerous studies have demonstrated that Notch signaling plays a critical role in cancer cells (21-24). It has been reported that Notch1 mediates radio-resistance of glioma stem cells and loss of Notch sensitizes those cells to ionizing radiation (25). However, whether Nrf2 mediated Notch1 downregulation plays a role in response to ionizing radiation remains elusive. 
Thus, the blocking of antioxidant responses could increase apoptotic death after radiotherapy. This study investigated the mechanism of the knockdown of Nrf2 enhancing radiationinduced apoptosis. We identified that Notch1 is strongly regulated by $\mathrm{Nrf} 2$ in response to IR and revealed that $\mathrm{Nrf} 2$ enhances radiation-induced apoptosis through downregulating the expression of Notch.

\section{Materials and methods}

Cell cultures. The human lung cancer cells (A549, NCI-H1299 (H1299), NCI-H460 (H460) were cultured in RPMI-1640 (Gibco Life Technologies, Carsbad, CA, USA) medium supplemented with $10 \%$ fetal bovine serum (Hyclone, GE Healthcare Life Sciences, Logan, UT, USA) and incubated at $37^{\circ} \mathrm{C}$ in a humidified air containing $5 \% \mathrm{CO}_{2}$.

Exposure to ionizing radiation. Cells were exposed to ionizing radiation at room temperature using Faxitron RX-650 $\mathrm{X}$-rays (Faxitron Bioptics, LLC, USA). The dose rates were $0.765 \mathrm{~Gy} / \mathrm{min}$.

Transfection. siRNA against Nrf2, Notch1 and non-targeting negative control siRNA were purchased from Invitrogen (Invitrogen Life Technologies, Carlsbad, CA, USA). Cells were seeded onto new plates one day prior to transfection. Transfection reagent was performed with Lipofectamine 2000 (Invitrogen Life Technologies), following the manufacturer's protocol. The serum-free medium was replaced with new culture medium for $6 \mathrm{~h}$ after transfection.

RNA isolation and reverse transcription. Total RNA was extracted from cultured cells by using TRIzol reagent (Takara Biotech Co., Ltd.) and reverse transcription was carried out using a PrimeScript RT Master Mix (Takara Biotech Co., Ltd.) in a total volume of $20 \mu \mathrm{l}$.

Real-time fluorescent quantitative PCR. Quantitative PCR was carried out with SYBR Premix Ex Taq II (Takara Biotech Co., Ltd.), 50 ng DNA and $10 \mu \mathrm{M}$ of each of the following primer pairs: Nrf2, 5'-AGCCCAGCACATCCAGTCA-3' (forward) and 5'-TGCATGCAGTCATCAAAGTACAAAG-3' (reverse), Hes1, 5'-GTGTCAACACGACACCGGATAAAC-3' (forward) and 5'-CAGAATGTCCGCCTTCTCCAG-3' (reverse), $\beta$-actin, 5'-TGGCACCCAGCACAATGAA-3' (forward) and 5'-CTAAGTCATAGTCCGCCTAGAAGCA-3' (reverse), $\beta$-actin for coding genes. The reaction was conducted on an FTC-3000 qPCR system (Shanghai Funglyn Biotech Co., Ltd.), with the following cycling conditions: $95^{\circ} \mathrm{C}$ for $30 \mathrm{sec}, 40$ cycles of $95^{\circ} \mathrm{C}$ for $5 \mathrm{sec}$ and $59^{\circ} \mathrm{C}$ for $30 \mathrm{sec}$. The expression of genes of interest was normalized to that of $\beta$-actin in all samples. Relative quantification approach $(\Delta \Delta \mathrm{Ct})$ was used to calculate the fold change.

Measurement of ROS generation. Intracellular ROS levels were assessed using $10 \mu \mathrm{M}$ 2',7'-dichlorofluorescin diacetate (DCFH-DA; Molecular Probes, Sigma), as described previously (26). Briefly, cells were treated for $30 \mathrm{~min}$ at $37^{\circ} \mathrm{C}$ in the dark. After incubation, cells were gently washed with PBS to remove the dye. Samples were observed with confocal microscopy (LSM700; Carl Zeiss) or harvested by trypsinization, washed, resuspended in $1 \mathrm{ml}$ of PBS, mean intensity was measured at an excitation wavelength of $488 \mathrm{~nm}$ and an emission wavelength of $525 \mathrm{~nm}$ using multimode reader (Thermo Varioskan Flash 3001).

Western blot analysis. Cells were washed with cold PBS and lysed with RIPA buffer (Beyotime, Haimen, China) with protease inhibitor cocktail. Cells were harvested for $30 \mathrm{~min}$ on ice and collected at $10,000 \mathrm{~g}$ for $15 \mathrm{~min}$ at $4^{\circ} \mathrm{C}$. The total concentrations of samples were measured using BCA protein assay kit (Pierce, Rockford, IL, USA). Equal amounts of protein were loaded onto $10 \%$ SDS-PAGE and proteins were transferred to an immobilon PVDF membrane (Roche). The membranes were then blocked with $0.05 \%$ Tween and 5\% BSA (BBI Life Sciences Corp., Canada) in Tris-buffered saline for $2 \mathrm{~h}$ at room temperature and incubated overnight at $4{ }^{\circ} \mathrm{C}$ with primary antibodies against Nrf2, GCLC, HO-1, NQO1, Bax, Bcl-2, cleaved (active) caspase-3, and PARP-1 cleavage (1:500, Cell Signaling Technology, Danvers, MA, USA). The preparative membranes were reacted with appropriate secondary antibodies conjugated to HRP. The immunological complexes were visualized with electrochemiluminescence (Millipore, Darmstadt, Germany). Band intensities were analyzed by ImageJ software.

Hoechst 33258 staining. Cells were washed twice with PBS and fixed with $4 \%$ paraformaldehyde for $20 \mathrm{~min}$ at room temperature. After washing twice with PBS, fixed cells were stained with Hoechst 33258 and incubated for $10 \mathrm{~min}$ in the dark and then washed with PBS. Apoptotic cells were identified by condensation and fragmentation of nuclei examined by fluorescence microscopy. Apoptotic cells were counted using cellprofiler 2.1.1 software (Broad Institute, Cambridge, MA, USA).

Immunofluorescence staining. Cells were pretreated $24 \mathrm{~h}$ with siRNA targeting Nrf2 and then exposed to 4 Gy of X-ray radiation. The medium was aspirated followed by three PBS washes. Using $4 \%$ paraformaldehyde, cells were fixed onto cover slips for $30 \mathrm{~min}$ at room temperature. Cells were rinsed three times with PBS and incubated with $0.5 \%$ Triton X-100 for $10 \mathrm{~min}$. The cells were washed three times and blocked with $0.1 \%$ BSA in PBS for $1 \mathrm{~h}$. Primary anti-Nrf2 antibody (Cell Signaling Technology) was added and incubated overnight at $4^{\circ} \mathrm{C}$. After three washes with PBS, the cells were incubated for $1 \mathrm{~h}$ at room temperature with the appropriate secondary antibody. After PBS washes, the slides were incubated with $0.5 \mathrm{mg} / \mathrm{ml}$ DAPI (4',6'-diamidino-2-phenylindole) at room temperature for $5 \mathrm{~min}$. All images were observed under a confocal microscope equipped with a digital camera (LSM700; Carl Zeiss).

Statistical analysis. Results are presented as mean \pm standard deviation (mean \pm SD). The data were analyzed using Student's t-tests. A p-value of $<0.05$ was considered statistically significant.

\section{Results}

Nrf2 is induced by ionizing radiation in A549 cells. Nrf2 is induced by external stimulation (15), such as IR. To investi- 
A

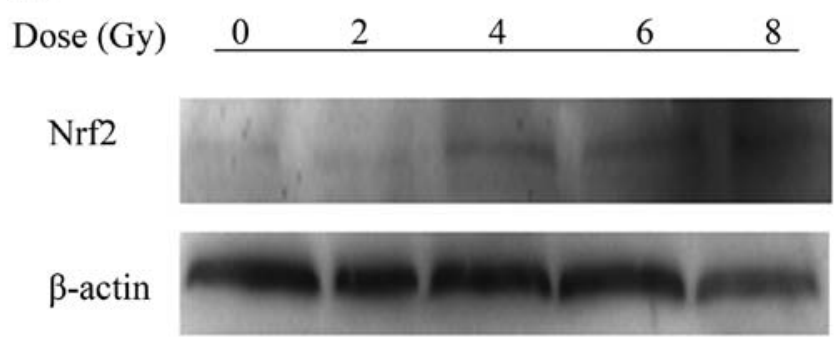

B

\begin{tabular}{lllllllll} 
Time (h) $\quad$ & 0 & 2 & 4 & 8 & 12 & 24 & 36 & 48 \\
\hline
\end{tabular}

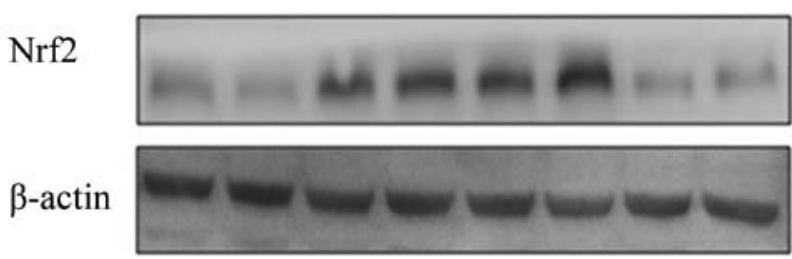

Figure 1. Nrf2 is induced in response to ionizing radiation in A549 cells (A) Various doses of ionizing radiation after $24 \mathrm{~h}$. (B) A single dose of $4 \mathrm{~Gy}$ that was analyzed at indicated time-points. $\beta$-actin was used as loading control. Results are from 3 experiments.

gate the effect of IR on Nrf2, A549 cells were irradiated with varying doses of $\mathrm{X}$-rays radiation. The protein expression levels of Nrf2 were measured by western blot analysis. The results showed that Nrf2 was induced in a dose-dependent manner from 4 to $8 \mathrm{~Gy}$. Furthermore, the expression of Nrf2 was increasingly elevated from 4 to $24 \mathrm{~h}$ after a single dose of 4 Gy (Fig. 1A and B). The effective dose was 4 Gy and the maximal effect was observed at $24 \mathrm{~h}$, therefore, we chose these parameters for our further experiments.

Knockdown of Nrf2 decreases radiation-upregulated Nrf2 in A549 cells. A549 cells were treated with non-targeting siRNA or siRNA specific to Nrf2 at 24, 48 and 72 . There were no significant changes in expression levels of the Nrf2 in cells transfected with a scrambled siRNA sequence (Fig. 2A). Whereas, both protein and mRNA levels were significantly decreased after being transfected with siRNA targeting Nrf2 (Fig. 2B and C). These results conveyed that the selected siRNA efficiently knocked down the expression of Nrf2, especially at $48 \mathrm{~h}$ time-point. Inhibition of Nrf2 by siRNA significantly decreased radiation-induced Nrf2 expression at mRNA levels (Fig. 3A). Nrf2 was localized at both the cytoplasm and the nucleus in control cells, but IR prominently stimulated translocation of Nrf 2 into the nucleus. Knockdown of Nrf2 significantly attenuated IR-induced Nrf2 nuclear translocation (Fig. 3B). Taken together, these results indicated that IR induced Nrf2 nuclear localization and this effect could be counteracted by Nrf2 knockdown.

Suppression of Nrf2 on the redox status. To further confirm the inhibitory effect of Nrf2 knockdown on antioxidant responses in A549 cells, we measured the function of the Nrf2 knockdown (Fig. 4). Notably, IR significantly increased Nrf2 target proteins GCLC, HO-1 and NQO1 expression in A549 lung cancer cells. Whereas, lowering Nrf2 expression levels led to a significantly decreased expression of Nrf2 target proteins GCLC, HO-1 and NQO1. These results showed that RNAi-mediated reduction of Nrf2, at least partly, decreasing the levels of antioxidant proteins induced by IR.

Knockdown of Nrf2 increases ROS accumulation after exposure. To determine whether the decrease in Nrf2 function increased ROS generation after exposure to IR, intracellular ROS levels were monitored using the fluorescent indicator
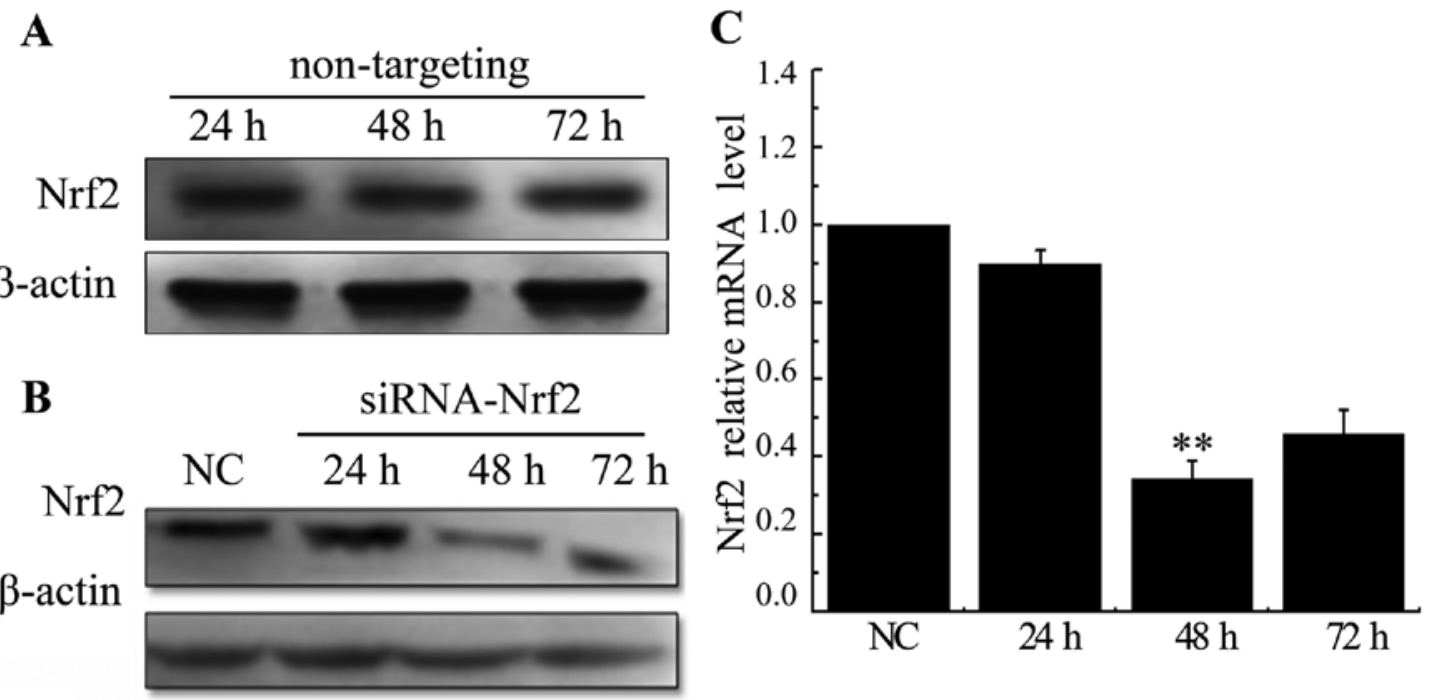

Figure 2. Downregulation of Nrf2 in A549 cells. (A) Western blot analysis for Nrf2 activation. Cells were harvested 24,48 and 72 h after transfection. $\beta$-actin served as normalization control. (B) Immunoblot showing reduced levels of endogenous Nrf 2 protein following transfection with siRNA targeting Nrf2 (siRNA-Nrf2) or negative control (NC). $\beta$-actin served as normalization control. (C) Nrf2 mRNA levels were monitored by quantitative RT-PCR at 24,48 and 72 h. ${ }^{* *} \mathrm{p}<0.01$ versus NC group. 
A

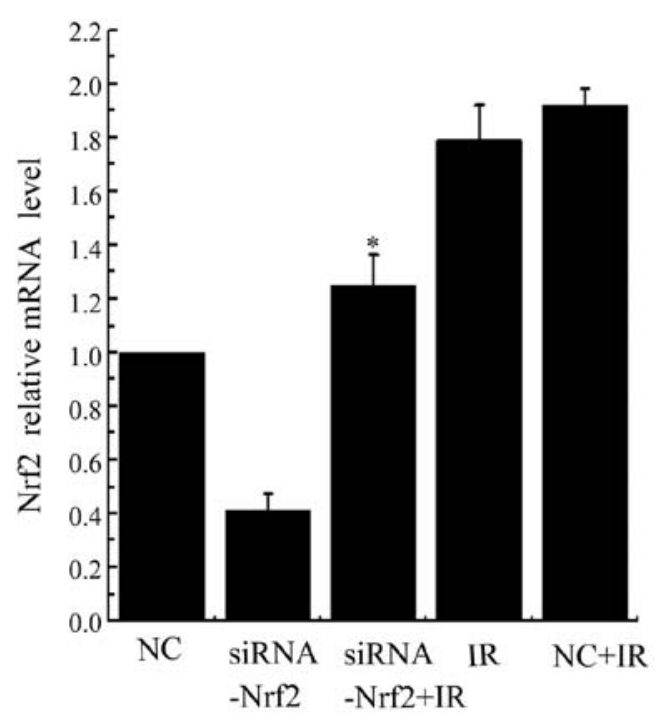

B

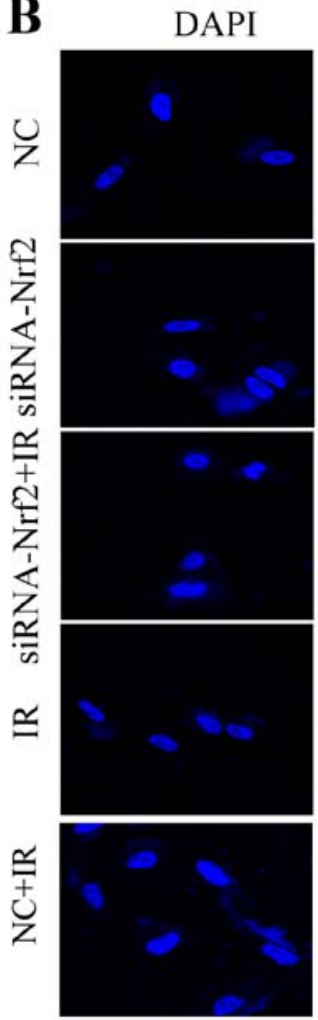

Nrf2
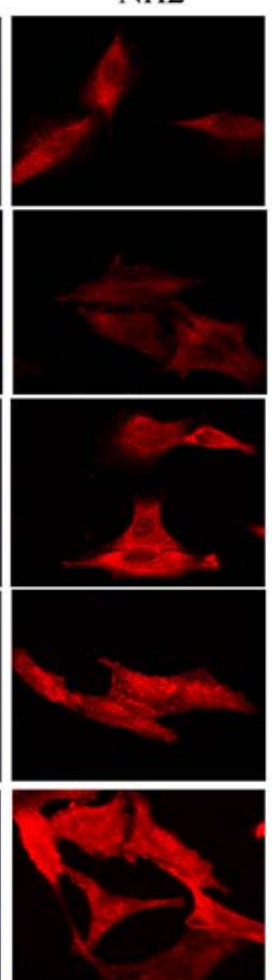
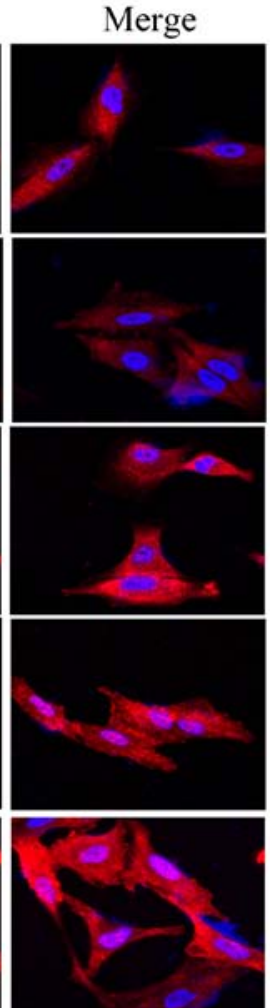

Figure 3. IR-induced nuclear translocation of Nrf2 is suppressed by siRNA-Nrf2 in A549 lung cancer cells. (A) mRNA levels of Nrf2 was determined by quantitative RT-PCR, at $24 \mathrm{~h}$ after exposing the cells to $4 \mathrm{~Gy}$ of X-ray irradiation. (B) Cells were treated with siRNA-Nrf2 before X-irradiation (4 Gy) and incubated for $24 \mathrm{~h}$. After staining with anti-Nrf2 antibody and Alexa Fluor 647-conjugated secondary antibody (red) and DAPI for nuclear staining (blue), cells were visualized under a fluorescence microscope. Data are representative of at least three different experiments. "p $<0.05$ versus NC+IR group alone.

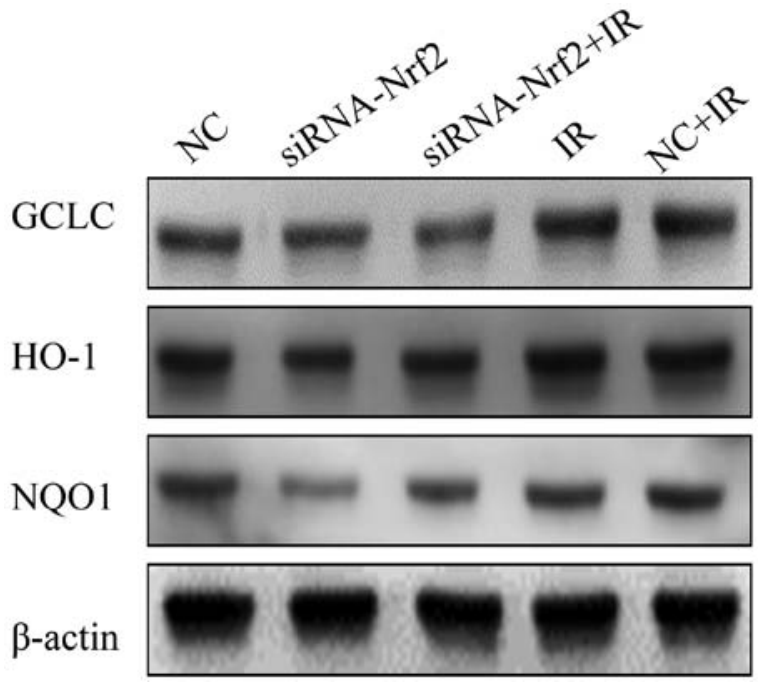

Figure 4. Effect of Nrf2 knockdown on the redox status in A549 cells. Immunoblot detection of GCLC, HO-1 and NQO1 at $24 \mathrm{~h}$ after exposure. $\beta$-actin was used as reference control. Experiments were repeated three times.

DCFH-DA at $24 \mathrm{~h}$ post irradiation in A549 cells. Knockdown of Nrf2 distinctly increased ROS after X-ray radiation as seen in confocal images and the mean fluorescent intensity (MFI) compared with NC+IR (Fig. 5). To some extent, lowering Nrf2 also effected the generation of ROS. Exposure to IR combined with knockdown of Nrf2 further enhanced the ROS produc- tion and increased the MFI compared to unirradiated cells. These results suggested that decreased Nrf2 activity enhanced the generation of ROS after irradiation.

Knockdown of Nrf2 decreased Notchl expression after IR. Previous studies have shown cross-talk between Nrf2 and the Notch pathway (27-31). To test whether Notch1 expression could be regulated by Nrf2 after irradiation, we treated A549 and H460 cells, which express Keap1 protein with different domain mutations, and H1299 cells, which express no mutation in Keap1. The expression of Notch1 was upregulated after radiation, while, in Nrf2 knockdown cells, Notch1 was debilitated (Fig. 6A). Furthermore, the expression of Hes1, a downstream gene in the Notch1 pathway (32), was reduced substantially after X-rays radiation in Nrf2 knockdown cells (Fig. 6B). We also demonstrated Notch1 was accumulated in A549 cells, but was reduced in Nrf2 expressing cells after irradiation. Collectively, these findings confirmed that Notch1 activation was abolished by the knockdown of Nrf2 in A549, H460 and H1299 cells.

Decrease in Nrf2 and Notchl increases IR-induced apoptosis. Bcl-2 family members, caspase-3 and PARP-1 are crucial mediators of apoptosis. To determine whether downregulation of Nrf2 and Notch1 following radiation induce apoptosis, we examined the expression of these mediators. Knockdown of Notch1 induced a sharp increase in the protein level of Bax, cleaved caspase- 3 and PARP-1 cleavage and a sharp decrease 


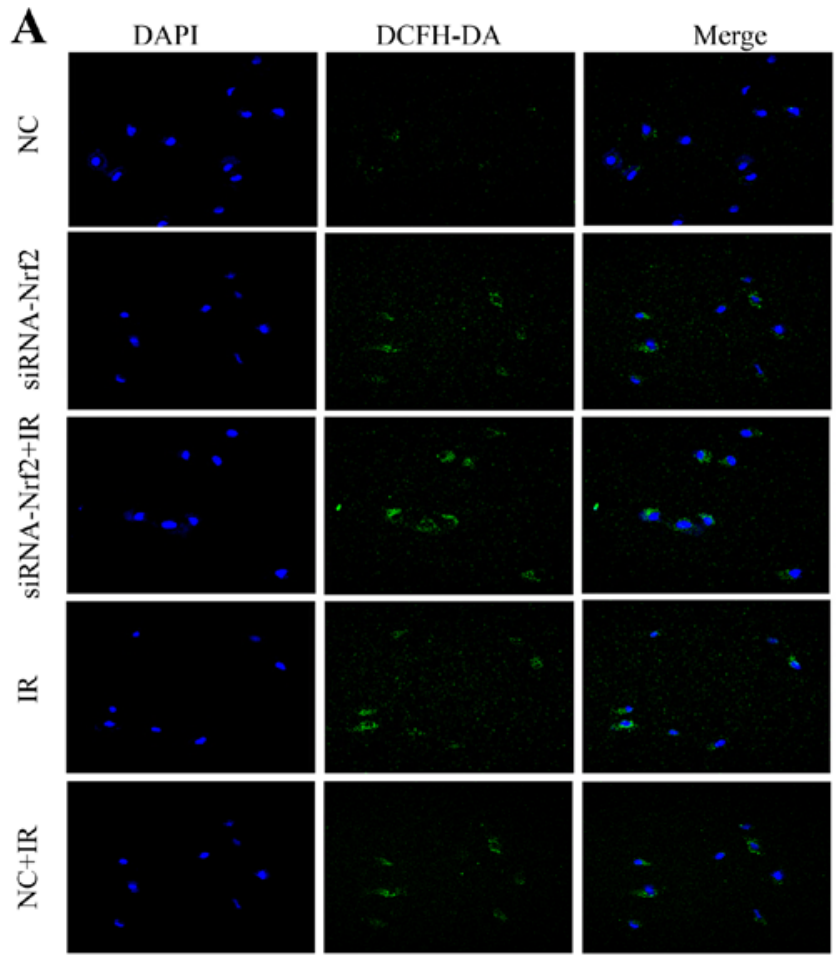

B

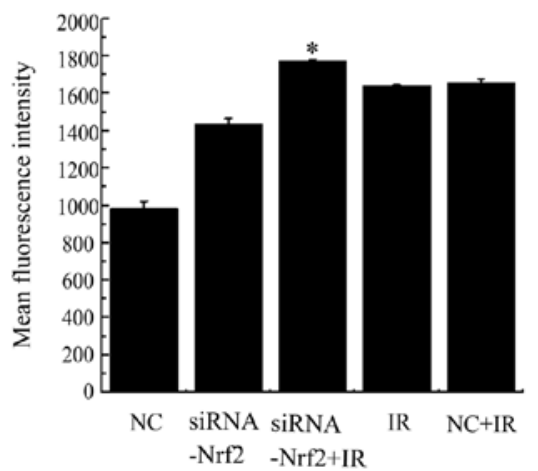

Figure 5. Suppression of Nrf2 activity enhances radiation-induced ROS accumulation in A549 cells. Intracellular ROS levels were determined $24 \mathrm{~h}$ postirradiation, (A) by fluorescence microscopy and (B) by a fluorescent microplate reader. " $\mathrm{p}<0.05$ versus NC+IR group alone.

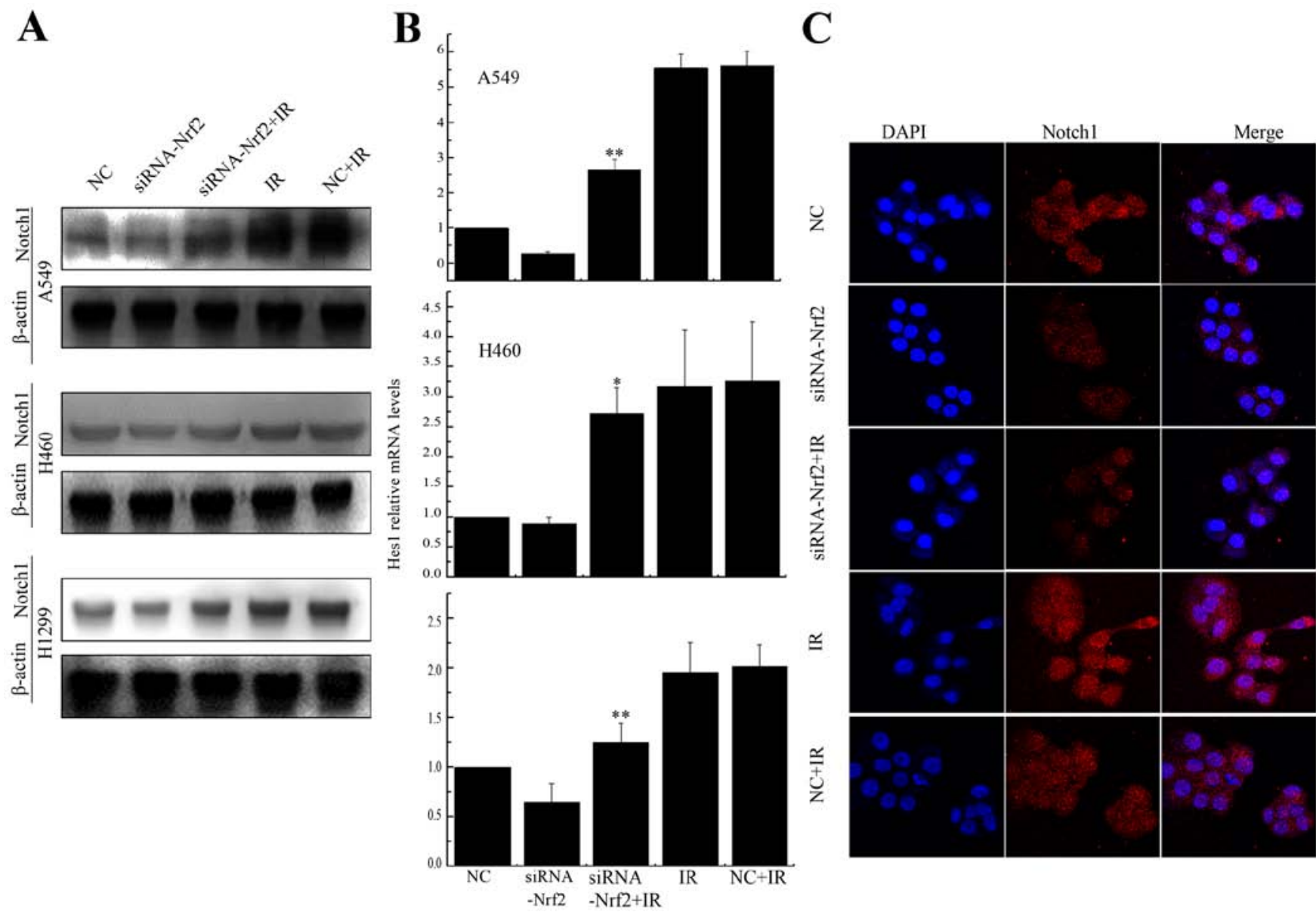

Figure 6. Expression of Notch1 and related gene in the knockdown of Nrf2 cells. (A) Quantification of protein expression. Notch1 were normalized by $\beta$-actin expression. (B) Hes1 mRNA levels were measured by quantitative RT-PCR. (C) Immunofluorescence staining for Notch1 in A549 cells, Alexa Fluor 647-conjugated secondary antibody (red) and nuclei were counterstained with DAPI (blue). Images were captured by confocal microscopy and merged. " p $<0.05$ and *"p $<0.01$ versus NC+IR group alone. 


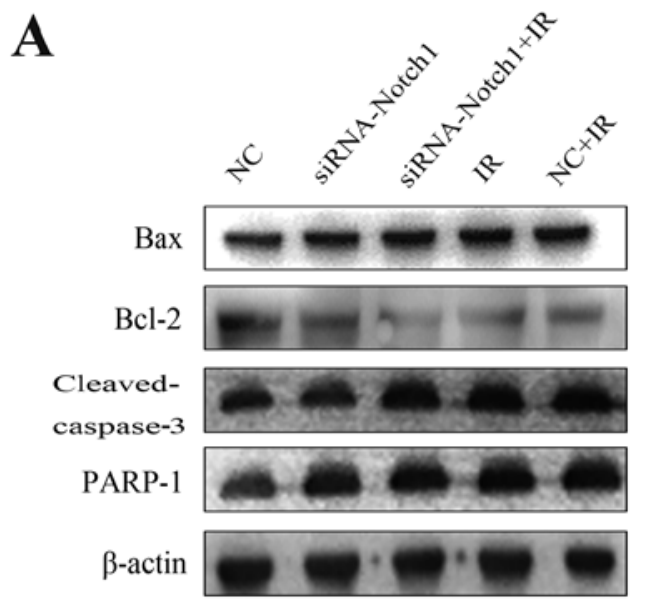

B
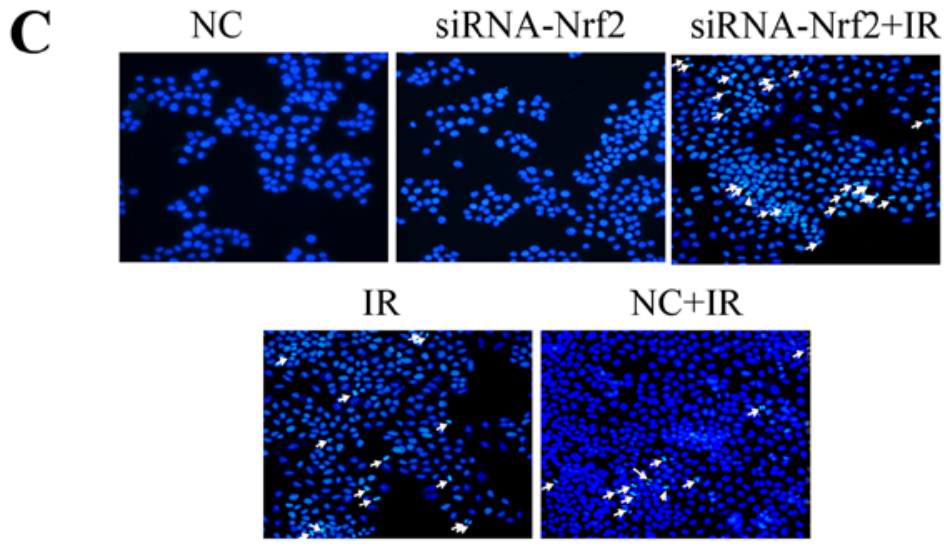

$\mathrm{NC}+\mathrm{IR}$

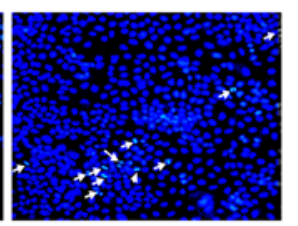

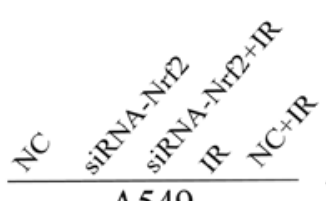

A549

Cleaved-

caspase- 3

PARP-1

$\beta$-actin
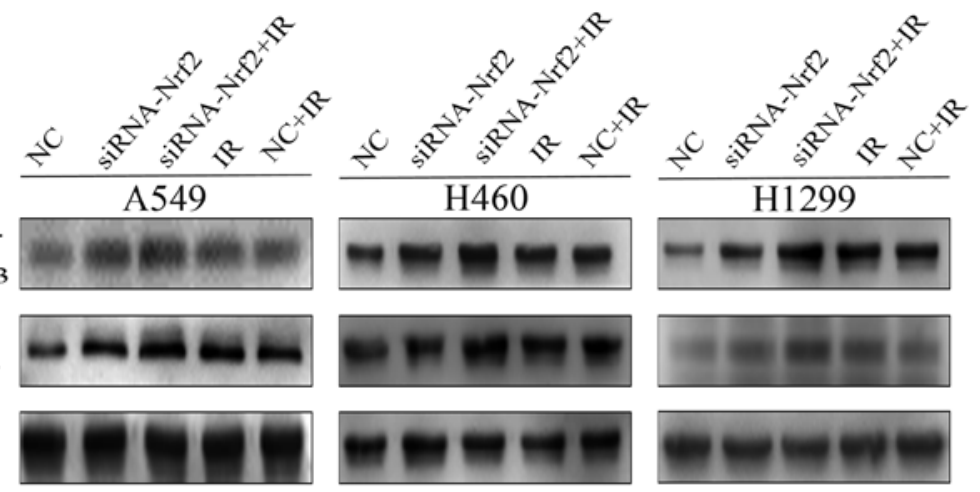

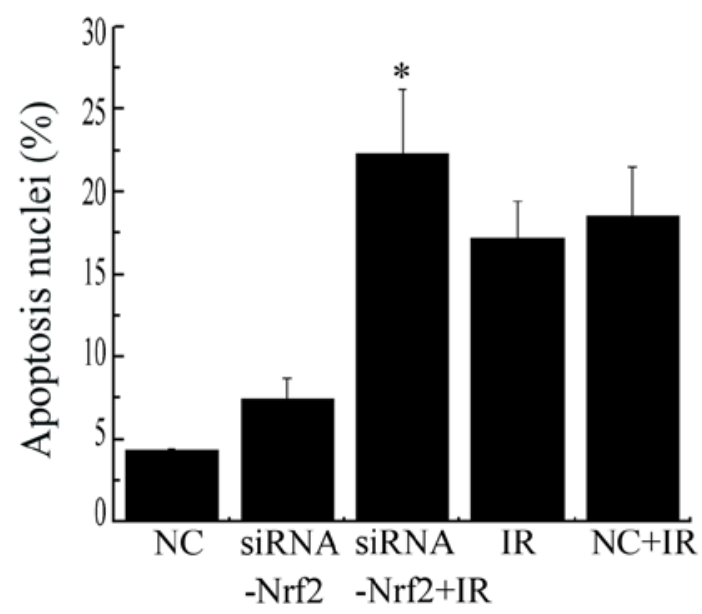

Figure 7. Nrf2 and Notch1 ablation potentiates apoptosis after irradiation. (A) A549, cell lysates were subjected to western blotting for the detection of Bax, Bcl-2, cleaved caspase-3 and PARP-1 activation. $\beta$-actin expression was utilized for normalization. (B) Western blot analysis for cleaved caspase-3 and PARP-1 activation. (C) The nuclear morphological changes by Hoechst 33258 staining were assessed. Arrows indicate chromatin condensation and nuclear fragmentation (x200 magnification) and the apoptotic rate of cell population. " $\mathrm{p}<0.05$ versus NC+IR group alone.

in the protein level of Bcl-2 after IR in A549 cells (Fig. 7A). Similarly, knockdown of Nrf2 enhanced radiation-induced cleaved caspase-3 and PARP-1 cleavage expression in all three cell lines (Fig. 7B). Furthermore, the nuclear morphological changes were also measured. Apoptotic cells showed a number of common features, such as cell shrinkage, nuclear condensation, and formation of pyknotic bodies of condensed chromatin. Suppression of Nrf2 resulted in a pronounced increase in cellular apoptosis after irradiation compared with NC+IR alone (Fig. 7C). Together, these findings suggest that lowering Nrf2 expression clearly facilitated IR induced apoptosis in NSCLC cell lines.

\section{Discussion}

The Keap1-Nrf2 signaling is the main cellular antioxidant system that regulates a broad spectrum of cytoprotective gene expression against oxidative injure, inflammation and apoptosis (33-36). Keap1 negatively regulates Nrf2 activity by promoting proteasomal degradation of Nrf2. Several reports demonstrated that Keap1 is present in somatic mutations leading to aberrant constitutive Nrf2 activation in
NSCLC cells (37-39). Activation of the Nrf2 pathway has been reported to mediate the radio-resistance of lung cancer (40). However, Notch1 regulates cell proliferation, invasion and apoptosis and its dysregulation leads to lung cancer initiation (41) and progression (42). Herein, we demonstrated that Nrf2 regulated the Notch signaling of NSCLC cells. The important finding was that Nrf2 and Notch1 promoted lung cancer cells to apoptosis in coordination.

$\mathrm{Nrf} 2$ can be stimulated by ionizing radiation. Several reports have shown that $\mathrm{Nrf} 2$ can be activated by ${ }^{137} \mathrm{Cs}$ exposure only after five day in MCF7 cell line (40) and was also induced at 0.1 Gy in Raw 264.7 cells (43). Recently, Nrf2 activation was observed within $6 \mathrm{~h}$ in $\mathrm{H} 1299$ cells (37). Various types of cells affect the activation of Nrf2. In this study, our results showed a dose-dependent increase of Nrf2 expression after irradiation and the minimum radiation dose inducing accumulation of Nrf2 was $4 \mathrm{~Gy}$. The level of Nrf2 increased at 4-24 h and was strongly elevated at $24 \mathrm{~h}$ after exposure to 4 Gy X-rays in A549 cells.

It is well accepted that IR enhance cell apoptosis, which is a major type of cell death. IR produces substantial amounts of intracellular ROS. In cancer cells, it is believed that ROS 


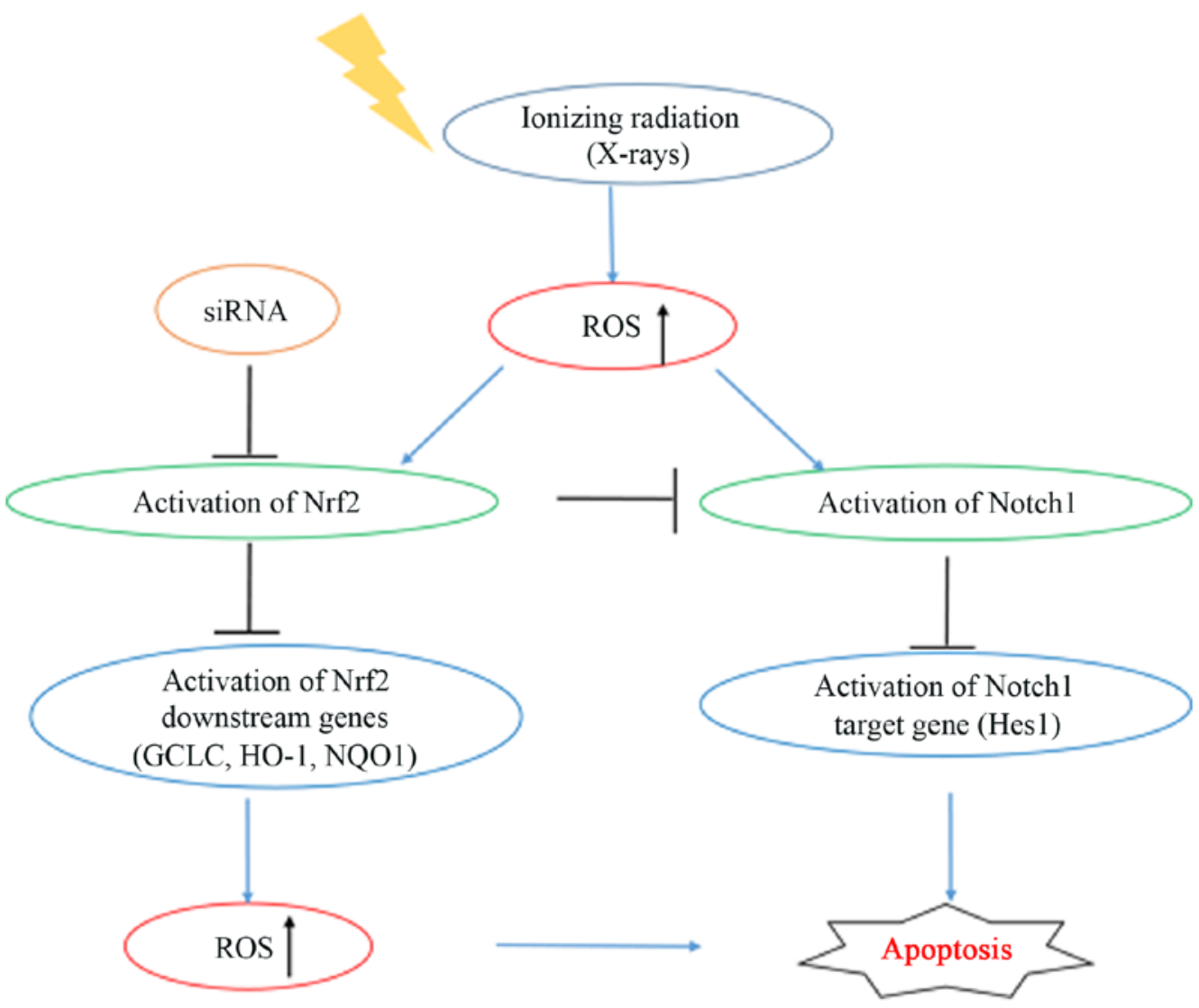

Figure 8. The proposed diagram representing knockdown of Nrf2 contributing to apoptosis of lung cancer cells.

induced genetic instability and is associated with oncogenic transformation (44). However, ROS must be eliminated to some extent, to avoid potential damage to DNA, and various cellular responses, including apoptosis and death. Diehn et al reported that enhanced ROS scavenger results in low ROS levels, and tumor radio-resistance (45). GCLC, HO-1 and NQO1 are Nrf2-regulated genes and protect against oxidative and xenobiotic stress by mopping up ROS (46-49). In our study, inhibition of Nrf2 significantly attenuated IR-induced Nrf2 nuclear translocation and decreased GCLC, HO-1 and NQO1 expression after irradiation. Our results indicated that decreased level of GCLC, HO-1 and NQO1 lead to increased ROS levels through weak antioxidant capacity. In response to external stimuli, a series of events lead to the stabilization of Nrf 2 and its translocation into the nucleus, where Nrf2 exerts its function and controls the expression of antioxidants. However, antioxidants could also regulate Nrf2 activation through feedback effects (50). In a Keap1 mutant cell line, Keap1 hardly regulates Nrf2 activation, and Nrf2 protein levels were high. When introducing exogenous siRNAs, Nrf2 is silenced and few Nrf2 activated, which suggest that Nrf2 nuclear translocation is at low level.

Nrf2 can cross-talk with other critical molecular pathways. Notch signaling is a candidate. Notch pathway influences cell fate determination $(21,51)$, and its activation is a mechanism of radiation resistance in breast cancer (52). Knockdown of Notch1 inhibited the self-renewal capacity in glioma cells $(53,54)$, induced apoptosis in NSCLC (41), and significantly increased cell death after X-ray irradiation
(25). Interestingly, Notch1 signaling could be regulated by Nrf2 $(16,27,28,30)$. Several reports have showed that Notch1 expression was reduced in Nrf2 knockout cells $(27,28)$. Nrf2 activated Notch1 signaling and regulated the repopulating capacity of hematopoietic stem progenitor cell (55). Thus, we speculated that there exists a mechanism with a different type of Nrf2 expressing lung cancer cells. For example, A549 and H460 cell lines express high level of Nrf2 $(16,39)$, while H1299 express wild-type Keap1 (37). Our results confirmed our speculation that decrease of Nrf2 mitigates the expression of Notch1 in NSCLC. Notch1 dramatically accumulates after exposure to X-rays. Loss of Nrf2 also reduced radiation-induced Notch1 and Hes1 activation. Our results showed that Notch1 ablation or IR activated the expression of cleaved caspase-3, PARP-1 and pro-apoptotic protein Bax, and decreased the expression of anti-apoptotic protein Bcl-2. Knockdown of Notch1 in A549 cells strongly increased the apoptosis proteins after irradiation. This indicated that loss of Notch1 increased irradiation-induced apoptosis. Similarly, lowering Nrf2 expression induced apoptosis after exposure through increased production of $\operatorname{ROS}(16,56)$. RNAi-mediated reduction of Nrf 2 could effectively promote cleaved caspase-3 and PARP-1 cleavage activation compared with IR alone in NSCLC cells. Nrf2-Notch pathway is a conserved pathway that is designed to allow cells to respond to the challenge of IR. It coincides with substantial research results, ROS, as inducer of Notch signaling, could activate Nrf2 signaling, which might play a dual trigger role in Nrf2Notch axis (57-59). It is reasonable to suggest that knockdown 
of Nrf2 induced production of ROS, thus promoted cellular apoptosis. Downregulation of Nrf2 reduced Notch1 expression, Notch1 also facilitated apoptosis. The double regulation impelled cells to undergo apoptosis.

No information exists regarding the role of Notch in Nrf2 knockdown in NSCLC cells under irradiation. Further investigation to examine the association between Nrf2 and Notch1 is required.

In conclusion, we have shown that knockdown of Nrf2 facilitated ROS generation by blocking cellular antioxidant abilities. Suppression of Nrf2 shows weaker expression of Notch1. These synergistic effect promoted IR-induced apoptosis. This study contributes to future strategies against lung cancer.

\section{Acknowledgements}

This study was supported by the Key Program of National Natural Science Foundation of China (U1432248) and the National Natural Science Foundation of China (11105203, 11305224).

\section{References}

1. Molina JR1, Yang P, Cassivi SD, Schild SE, and Adjei AA: Non-small cell lung cancer: Epidemiology, risk factors, treatment, and survivorship. Mayo Clin Proc 83: 584-594, 2008.

2. Ferlay J, Steliarova-Foucher E, Lortet-Tieulent J, Rosso S, Coebergh JW, Comber H, Forman D and Bray F: Cancer incidence and mortality patterns in Europe: Estimates for 40 countries in 2012. Eur J Cancer 49: 1374-1403, 2013.

3. Bareschino MA, Schettino C, Rossi A, Maione P, Sacco PC, Zeppa R and Gridelli C: Treatment of advanced non small cell lung cancer. J Thorac Dis 3: 122-133, 2011.

4. Hensley K and Floyd RA: Reactive oxygen species and protein oxidation in aging: A look back, a look ahead. Arch Biochem Biophys 397: 377-383, 2002.

5. Nadkar A, Pungaliya C, Drake K, Zajac E, Singhal SS and Awasthi S: Therapeutic resistance in lung cancer. Expert Opin Drug Metab Toxicol 2: 753-777, 2006.

6. Kensler TW and Wakabayashi N: Nrf2: Friend or foe for chemoprevention? Carcinogenesis 31: 90-99, 2010.

7. Kovac S, Angelova PR, Holmström KM, Zhang Y, DinkovaKostova AT and Abramov AY: Nrf2 regulates ROS production by mitochondria and NADPH oxidase. Biochim Biophys Acta 1850: 794-801, 2015.

8. Zhou R, Lin J and Wu D: Sulforaphane induces Nrf2 and protects against CYP2E1-dependent binge alcohol-induced liver steatosis. Biochim Biophys Acta 1840: 209-218, 2014.

9. Huber S, Valente S, Chaimbault P and Schohn H: Evaluation of $\Delta 2$-pioglitazone, an analogue of pioglitazone, on colon cancer cell survival: Evidence of drug treatment association with autophagy and activation of the Nrf2/Keap1 pathway. Int J Oncol 45: 426-438, 2014

10. Shibata T, Ohta T, Tong KI, Kokubu A, Odogawa R, Tsuta K, Asamura $\mathrm{H}$, Yamamoto $\mathrm{M}$ and Hirohashi S: Cancer related mutations in NRF2 impair its recognition by Keap1-Cul3 E3 ligase and promote malignancy. Proc Natl Acad Sci USA 105: 13568-13573, 2008.

11. Wang P, Peng X, Wei ZF, Wei FY, Wang W, Ma WD, Yao LP, $\mathrm{Fu}$ YJ and Zu YG: Geraniin exerts cytoprotective effect against cellular oxidative stress by upregulation of Nrf2-mediated antioxidant enzyme expression via PI3K/AKT and ERK1/2 pathway. Biochim Biophys Acta 1850: 1751-1761, 2015.

12. Ding M, Zhao J, Bowman L, Lu Y and Shi X: Inhibition of AP-1 and MAPK signaling and activation of Nrf2/ARE pathway by quercitrin. Int J Oncol 36: 59-67, 2010.

13. Alam J, Stewart D, Touchard C, Boinapally S, Choi AM and Cook JL: Nrf2, a Cap'n'Collar transcription factor, regulates induction of the heme oxygenase-1 gene. J Biol Chem 274 26071-26078, 1999.
14. Kansanen E, Kuosmanen SM, Leinonen $H$ and Levonen A-L: The Keap1-Nrf2 pathway: Mechanisms of activation and dysregulation in cancer. Redox Biol 1: 45-49, 2013.

15. Rana T, Schultz MA, Freeman ML and Biswas S: Loss of Nrf2 accelerates ionizing radiation-induced bone loss by upregulating RANKL. Free Radic Biol Med 53: 2298-2307, 2012.

16. Singh A, Boldin-Adamsky S, Thimmulappa RK, Rath SK, Ashush H, Coulter J, Blackford A, Goodman SN, Bunz F, Watson WH, et al: RNAi-mediated silencing of nuclear factor erythroid-2-related factor 2 gene expression in non-small cell lung cancer inhibits tumor growth and increases efficacy of chemotherapy. Cancer Res 68: 7975-7984, 2008.

17. Greenwald I: LIN-12/Notch signaling: Lessons from worms and flies. Genes Dev 12: 1751-1762, 1998.

18. Artavanis-Tsakonas S, Rand MD and Lake RJ: Notch signaling: Cell fate control and signal integration in development. Science 284: 770-776, 1999.

19. Wang X, Zhang J, Zhou L, Sun W, Zheng ZG, Lu P, Gao Y, Yang XS, Zhang ZC, Tao KS, et al: Fbxw7 regulates hepatocellular carcinoma migration and invasion via Notch1 signaling pathway. Int J Oncol 47: 231-243, 2015.

20. Xue TC, Zou JH, Chen RX, Cui JF, Tang ZY and Ye SL: Spatial localization of the JAG1/Notch1/osteopontin cascade modulates extrahepatic metastasis in hepatocellular carcinoma. Int J Oncol 45: 1883-1890, 2014.

21. Ayaz F and Osborne BA: Non-canonical notch signaling in cancer and immunity. Front Oncol 4: 345, 2014.

22. Swiatek PJ, Lindsell CE, del Amo FF, Weinmaster G and Gridley T: Notch1 is essential for postimplantation development in mice. Genes Dev 8: 707-719, 1994.

23. Fre S, Huyghe M, Mourikis P, Robine S, Louvard D and Artavanis-Tsakonas S: Notch signals control the fate of immature progenitor cells in the intestine. Nature 435: 964-968, 2005.

24. Ersvaer E, Hatfield KJ, Reikvam H and Bruserud O: Future perspectives: Therapeutic targeting of notch signalling may become a strategy in patients receiving stem cell transplantation for hematologic malignancies. Bone Marrow Res 2011: 570796, 2011.

25. Wang J, Wakeman TP, Lathia JD, Hjelmeland AB, Wang XF, White RR, Rich JN and Sullenger BA: Notch promotes radioresistance of glioma stem cells. Stem Cells 28: 17-28, 2010.

26. Bataller R, Schwabe RF, Choi YH, Yang L, Paik YH, Lindquist J, Qian T, Schoonhoven R, Hagedorn CH, Lemasters JJ, et al: NADPH oxidase signal transduces angiotensin II in hepatic stellate cells and is critical in hepatic fibrosis. J Clin Invest 112: 1383-1394, 2003.

27. Wakabayashi N, Skoko JJ, Chartoumpekis DV, Kimura S, Slocum SL, Noda K, Palliyaguru DL, Fujimuro M, Boley PA, Tanaka Y, et al: Notch-Nrf2 axis: Regulation of Nrf2 gene expression and cytoprotection by notch signaling. Mol Cell Biol 34: 653-663, 2014.

28. Wakabayashi N, Shin S, Slocum SL, Agoston ES, Wakabayashi J, Kwak MK, Misra V, Biswal S, Yamamoto M and Kensler TW: Regulation of notch1 signaling by Nrf2: Implications for tissue regeneration. Sci Signal 3: ra52, 2010.

29. Paul MK, Bisht B, Darmawan DO, Chiou R, Ha VL, Wallace WD, Chon AT, Hegab AE, Grogan T, Elashoff DA, et al: Dynamic changes in intracellular ROS levels regulate airway basal stem cell homeostasis through Nrf2-dependent Notch signaling. Cell Stem Cell 15: 199-214, 2014.

30. Kim JH, Thimmulappa RK, Kumar V, Cui W, Kumar S, Kombairaju P, Zhang H, Margolick J, Matsui W, Macvittie T, et al: NRF2-mediated Notch pathway activation enhances hematopoietic reconstitution following myelosuppressive radiation. J Clin Invest 124: 730-741, 2014.

31. Wakabayashi N, Chartoumpekis DV and Kensler TW: Crosstalk between Nrf2 and Notch signaling. Free Radic Biol Med 88B: 158-167, 2015.

32. Iso T, Kedes L and Hamamori Y: HES and HERP families: Multiple effectors of the Notch signaling pathway. J Cell Physiol 194: 237-255, 2003.

33. Yang H, Ramani K, Xia M, Ko KS, Li TW, Oh P, Li J and Lu SC: Dysregulation of glutathione synthesis during cholestasis in mice: Molecular mechanisms and therapeutic implications. Hepatology 49: 1982-1991, 2009.

34. Tan Y, Ichikawa T, Li J, Si Q, Yang H, Chen X, Goldblatt CS, Meyer CJ, Li X, Cai L, et al: Diabetic downregulation of Nrf2 activity via ERK contributes to oxidative stress-induced insulin resistance in cardiac cells in vitro and in vivo. Diabetes 60 : 625-633, 2011. 
35. Goldring CE, Kitteringham NR, Elsby R, Randle LE, Clement YN, Williams DP, McMahon M, Hayes JD, Itoh K, Yamamoto M, et al: Activation of hepatic Nrf2 in vivo by acetaminophen in CD-1 mice. Hepatology 39: 1267-1276, 2004.

36. Rizvi F, Mathur A and Kakkar P: Morin mitigates acetaminophen-induced liver injury by potentiating Nrf2 regulated survival mechanism through molecular intervention in PHLPP2-AktGsk3beta axis. Apoptosis 20: 1296, 2015.

37. Lee S, Lim MJ, Kim MH, Yu CH, Yun YS, Ahn J and Song JY: An effective strategy for increasing the radiosensitivity of Human lung Cancer cells by blocking Nrf2-dependent antioxidant responses. Free Radic Biol Med 53: 807-816, 2012.

38. Singh A, Bodas M, Wakabayashi N, Bunz F and Biswal S: Gain of Nrf2 function in non-small-cell lung cancer cells confers radioresistance. Antioxid Redox Signal 13: 1627-1637, 2010.

39. Singh A, Misra V, Thimmulappa RK, Lee H, Ames S, Hoque MO, Herman JG, Baylin SB, Sidransky D, Gabrielson E, et al: Dysfunctional KEAP1-NRF2 interaction in non-small-cell lung cancer. PLoS Med 3: e420, 2006.

40. McDonald JT, Kim K, Norris AJ, Vlashi E, Phillips TM, Lagadec C, Della Donna L, Ratikan J, Szelag H, Hlatky L, et al: Ionizing radiation activates the $\mathrm{Nrf} 2$ antioxidant response. Cancer Res 70: 8886-8895, 2010.

41. Licciulli S, Avila JL, Hanlon L, Troutman S, Cesaroni M, Kota S, Keith B, Simon MC, Puré E, Radtke F, et al: Notch1 is required for Kras-induced lung adenocarcinoma and controls tumor cell survival via p53. Cancer Res 73: 5974-5984, 2013.

42. Donnem T, Andersen S, Al-Shibli K, Al-Saad S, Busund LT and Bremnes RM: Prognostic impact of Notch ligands and receptors in nonsmall cell lung cancer: Coexpression of Notch-1 and vascular endothelial growth factor-A predicts poor survival. Cancer 116: 5676-5685, 2010.

43. Tsukimoto M, Tamaishi N, Homma T and Kojima S: Low-dose gamma-ray irradiation induces translocation of $\mathrm{Nrf} 2$ into nuclear in mouse macrophage RAW264.7 cells. J Radiat Res (Tokyo) 51: 349-353, 2010

44. Ettinger DS, Wood DE, Akerley W, Bazhenova LA, Borghaei H, Camidge DR, Cheney RT, Chirieac LR, D'Amico TA, Demmy TL, et al: Non-small cell lung cancer, version 6.2015. J Natl Compr Cancer Netw 13: 515-524, 2015.

45. Diehn M, Cho RW, Lobo NA, Kalisky T, Dorie MJ, Kulp AN, Qian D, Lam JS, Ailles LE, Wong M, et al: Association of reactive oxygen species levels and radioresistance in cancer stem cells. Nature 458: 780-783, 2009.

46. Caro AA, Commissariat A, Dunn C, Kim H, García SL, Smith A, Strang H, Stuppy J, Desrochers LP and Goodwin TE: Prooxidant and antioxidant properties of salicylaldehyde isonicotinoyl hydrazone iron chelators in HepG2 cells. Biochim Biophys Acta 1850: 2256-2264, 2015.

47. Hwang GH, Ryu JM, Jeon YJ, Choi J, Han HJ, Lee YM, Lee S, Bae JS, Jung JW, Chang W, et al: The role of thioredoxin reductase and glutathione reductase in plumbagin-induced, reactive oxygen species-mediated apoptosis in cancer cell lines. Eur J Pharmacol 765: 384-393, 2015.
48. Ernst IM, Schuemann C, Wagner AE and Rimbach G: 3,3'-Diindolylmethane but not indole-3-carbinol activates Nrf2 and induces Nrf2 target gene expression in cultured murine fibroblasts. Free Radic Res 45: 941-949, 2011

49. Zhang Y, Guan L, Wang X, Wen T, Xing J and Zhao J: Protection of chlorophyllin against oxidative damage by inducing HO-1 and NQO1 expression mediated by PI3K/Akt and Nrf2. Free Radic Res 42: 362-371, 2008

50. Schmidt EE: Interplay between cytosolic disulfide reductase systems and the Nrf2/Keap1 pathway. Biochem Soc Trans 43: 632-638, 2015.

51. Bi P and Kuang S: Notch signaling as a novel regulator of metabolism. Trends Endocrinol Metab 26: 248-255, 2015.

52. Phillips TM, McBride WH and Pajonk F: The response of $\mathrm{CD} 24(-/$ low $) / \mathrm{CD} 44^{+}$breast cancer-initiating cells to radiation. J Natl Cancer Inst 98: 1777-1785, 2006.

53. Purow BW, Haque RM, Noel MW, Su Q, Burdick MJ, Lee J, Sundaresan T, Pastorino S, Park JK, Mikolaenko I, et al: Expression of Notch-1 and its ligands, Delta-like-1 and Jagged-1, is critical for glioma cell survival and proliferation. Cancer Res 65: 2353-2363, 2005.

54. Farnie G, Clarke RB, Spence K, Pinnock N, Brennan K, Anderson NG and Bundred NJ: Novel cell culture technique for primary ductal carcinoma in situ: Role of Notch and epidermal growth factor receptor signaling pathways. J Natl Cancer Inst 99: 616-627, 2007.

55. Kim JH, Thimmulappa RK, Kumar V, Cui W, Kumar S, Kombairaju P, Zhang H, Margolick J, Matsui W, Macvittie T, et al: NRF2-mediated Notch pathway activation enhances hematopoietic reconstitution following myelosuppressive radiation. J Clin Invest 124: 730-741, 2014

56. Kim W, Youn H, Kang C and Youn B: Inflammation-induced radioresistance is mediated by ROS-dependent inactivation of protein phosphatase 1 in non-small cell lung cancer cells. Apoptosis 20: 1242-1252, 2015.

57. Servettaz A, Goulvestre C, Kavian N, Nicco C, Guilpain P, Chéreau C, Vuiblet V, Guillevin L, Mouthon L, Weill B, et al: Selective oxidation of DNA topoisomerase 1 induces systemic sclerosis in the mouse. J Immunol 182: 5855-5864, 2009.

58. Kavian N, Servettaz A, Mongaret C, Wang A, Nicco C, Chéreau C, Grange P, Vuiblet V, Birembaut P, Diebold MD, et al: Targeting ADAM-17/notch signaling abrogates the development of systemic sclerosis in a murine model. Arthritis Rheum 62: 3477-3487, 2010

59. Kavian N, Servettaz A, Weill B and Batteux F: New insights into the mechanism of notch signalling in fibrosis. Open Rheumatol J 6: 96-102, 2012. 